\title{
Utility of agro-residues to produce xylanase by Penicillium citrinum MTCC 9620 in solid state fermentation
}

Jyosthna Khanna Goli and Hameeda Bee*

Department of Microbiology, Osmania University, Hyderabad- 500007

*Corresponding author Email: drhami2009@gmail.com

(Submitted on September 5, 2020; Accepted on November 27, 2020)

\begin{abstract}
Wheat bran was found to be the best substrate, for cellulase free endo-1, $4-\beta$-xylanase production by solid state fermentation (SSF) using Penicillium citrinum MTCC 9620. One factor at a time (OFAT) approach was carried out to optimize process parameters for xylanase production by SSF, resulting in xylanase production of $405 \mathrm{U} / \mathrm{gds}$ after $96 \mathrm{~h}$ of incubation at $30^{\circ} \mathrm{C}, 80 \%$ moisture with urea as source of nitrogen and maltose as a co-substrate (additional carbon source). Further, statistical approach by Box-Behnken design was used for optimization of $\mathrm{pH}$, incubation time, biomass concentration and moisture content to obtain maximum xylanase yield of $1225 \mathrm{U} / \mathrm{gds}$ at $\mathrm{PH} 6$, with $1 \mathrm{~g}$ biomass, $\mathbf{8 0} \%$ moisture and incubation time of 4 days, respectively. The xylanase production by statistical approach was found to be 3 fold higher in comparison to OFAT approach.
\end{abstract}

KEYWORDS: Solid state fermentation, OFAT, statistical approach, optimization, Box Behnken design

\section{INTRODUCTION}

Lignocelluloses are widely available attractive and renewable resource found on the earth. Usage of agricultural residues as substrates for production of value-added products like biofuel, xylitol and xylanases is economical and pollution free (Pandiyan et al., 2019). Lignocelluloses are complex polymers consisting of Celluloses, hemicelluloses, and lignin. Cellulose and hemicellulose are the major carbohydrate sources which on degradation release simple sugars which are essential in the development of microbes and synthesis of enzymes (dos Santos et al., 2016). Xylan is present as a major part of the hemicellulose; they are homopolymers with D-xylose monomers linked by $\beta-1$, 4-glycosyl bonds. Complete and proficient biodegradation of xylan needs group of enzymes called xylanolytic system. The important among them is endo- $1,4-\beta$-xylanase $(1,4-\beta$ - D-xylan xylanohydrolases, EC 3.2.1.8) which hydrolyzes the xylan backbone and release xylose and xylobiose (Kandaswamy et al., 2016). Majority of xylanases are produced by microbes like bacteria, yeast, and fungi. However, fungi such as Aspergillus sp., Trichoderma and Penicillium were of importance due to their high xylanase yield and stability (Maheshwari et al., 2000). Microbial xylanases have gained its attention due to their application in conversion of lignocellulosic biomass to valuable compounds like xylitol and bioethanol. It also has its applications in clarification of fruit juices, bio-bleaching, and in paper and pulp industry (Maheswari et al., 2000; Chadha et al., 2019). More recently focus for xylanolytic enzymes production is increasing due to their efficient digestibility of feed stock. Xylanases hydrolyze cell wall polysaccharides, they degrade xylan in such a way that they become highly soluble and improve the viscosity of the dough (Sharma and Kumar, 2013). Hence xylanases were found to be useful in bread making industry to improve the texture (Santala et al., 2011). Production of xylanases can be accomplished by submerged fermentation (SMF) or solid-state fermentation (SSF). Production of xylanase by SSF is advantageous over SMF as it is economical with high productivity and easy downstream processing. Enzyme produced by SSF is more stable with low risk of contamination and mimics the natural habit of the fungus which enable them to grow relatively at a high pace.
Wheat bran, a byproduct of wheat, constitutes significant amount of underutilized sugars. Annually 650 tons of wheat is produced worldwide which account to approximately 150 million tons of accumulated biomass (Pruckler et al., 2014). Wheat bran is being used for xylanase production as it activates xylanases with $40 \%$ xylan in their polysaccharide cell wall favouring degradability and contains few nutrients which serve as carbon source. Wheat bran provides large surface area by remaining loose when moistened (Knob et al., 2014).

Initially, one factor at a time (OFAT), a conventional method of varying one variable keeping others constant was performed for optimization of xylanase production. However, this method is cumbersome and do not show the interaction between variables (Gupta et al., 2012). Thus, statistical design such as RSM which show the interaction between the variables and can be performed by reduced number of experiments and analysis time is also useful for optimization (Govarthanan et al., 2015).

The objective of the present study is to optimize the production of cellulase free xylanase from wheat bran, as lignocellulosic biomass using P. citrinum MTCC 9620.

\section{MATERIALS AND METHODS}

Raw material: Various agro-residues are collected from different areas of Mandapur and Tadkapally villages of Telangana state. The biomass was washed under running water, air dried and grounded into mesh size of 0.5-1 $\mathrm{mm}$ and oven dried till it attains constant moisture and stored until use.

Microorganism: Pencillium citrinum (MTCC 9620) was procured from IMTECH Chandigarh and maintained on Yeast Peptone xylose agar medium (YPEX) slants containing $(\mathrm{g} / \mathrm{L})$ yeast 10 , Peptone 20, xylose 30 , agar 25 with $\mathrm{pH} 5$ and the slants were stored at $4^{\circ} \mathrm{C}$ and sub- cultured after every two weeks.

Qualitative test for xylanase production: Qualitative test by agar diffusion method was conducted for xylanase production by $P$. citrinum (9620). Sterile modified mandels mineral salt medium (MMS) plates (100 mL of MMS medium containing $1 \%$ oat spelt xylan and $2.5 \%$ agar) were inoculated with loopful culture and incubated at $30^{\circ} \mathrm{C}$ for $48 \mathrm{~h}$. Production of 
xylanase was observed in the form of zones of clearance, when the plates were flooded with $1 \%(\mathrm{w} / \mathrm{v})$ Congo red and placed for $15 \mathrm{~min}$ and later destained with $1 \mathrm{M} \mathrm{NaCl}$.

Screening of agro-residues: Agro-residues like rice husk, corn fiber, wheat bran, cotton stalks and ground nut husk are screened and the biomass substrate with maximum xylanase activity was used for further experiments.

SSF for xylanase production: Biomass substrate 1\% (w/v) was taken in $100 \mathrm{~mL}$ flask and added with modified MMS medium (Mandels and Reese, 1957) containing (g/L) $\mathrm{NH}_{4} \mathrm{SO}_{4}-1.4 ; \mathrm{CaCl}_{2}-0.4 ; \mathrm{Kh}_{2} \mathrm{PO}_{4}-2 \mathrm{~g} ; \mathrm{MgSO}_{4}-0.3 \mathrm{~g}$; peptone-1; Tween 80-0.2mL; $\mathrm{FeSO}_{4}-0.05 ; \mathrm{MnSO}_{4}-0.06$; Urea-0.3 and adjusted to $\mathrm{pH} 6$. The flasks are sterilized at $121^{\circ} \mathrm{C}$ for $15 \mathrm{~min}$ by autoclaving and further inoculated with $1 \mathrm{~mL}$ inoculum made by harvesting $P$. citrinum aseptically from slants using saline water containing $0.01 \%$ tween 80 so that the concentration of the spores in the inoculum is $1 \times 10^{6}$. Once inoculated, the flasks were tapped so that the substrate is evenly mixed with the inoculum and later incubated at $30^{\circ} \mathrm{C}$ for 6 days in still condition. Sampling was done after every 24 $\mathrm{h}$ and the crude enzyme harvested was estimated for xylanase production.

Harvesting enzyme: The enzyme was harvested after every $24 \mathrm{~h}$ from respective flasks using extraction buffer (sodium acetate, $\mathrm{pH} 4.8)$ in $1: 10(\mathrm{w} / \mathrm{v})$ of substrate to extraction buffer and were incubated for $1 \mathrm{~h}$ by shaking on a rotary shaker maintained at $150 \mathrm{rpm}$. The solid biomass was removed by filtration using sterile muslin cloth. Later the filtrate with the suspended spores or leftover solids was centrifuged at $7000 \mathrm{~g}$ for $10 \mathrm{~min}$ and the clear supernatant obtained was used as crude enzyme in the assay for xylanase activity.

Xylanase assay: Xylanase assay was carried out according to 'Bailey et al. (1992) method'. For this $0.2 \mathrm{~mL}$ of crude enzyme and $1.8 \mathrm{~mL}$ of $1 \%$ oat spelt xylan (used as substrate) are added into the tube and incubated in water bath maintained at $50^{\circ} \mathrm{C}$ for $20 \mathrm{~min} .0 .5 \mathrm{~mL}$ of 3,5 dinitrosalicylic acid reagent (DNS) was added to stop the reaction and the released xylose sugars are estimated by using UV-VIS spectrophotometer to measure the absorbance at $540 \mathrm{~nm}$ (Miller, 1959). The Protein concentration is determined by the Lowry (1951) method using bovine serum albumin (Sigma-Aldrich) as standard. Under standard assay condition, one international unit (IU) of xylanase activity is defined as the quantity of the enzyme needed to release $1 \mu \mathrm{mol}$ of xylose from xylan per minute.

Filter paper assay: The activity of cellulase present in the crude enzyme was estimated by mixing $0.5 \mathrm{~mL}$ of acetate buffer with $0.05 \mathrm{~g}$ of Whatman filter paper (used as substrate) and $0.5 \mathrm{~mL}$ of crude enzyme in the tube at $50^{\circ} \mathrm{C}$ for $15 \mathrm{~m}$ and the reaction was stopped by addition of DNS. Later the tube was placed in boiling water bath for $5 \mathrm{~min}$, cooled and amount of sugar released was estimated at 540 nm using spectrophotometer.

\section{OPTIMIZATION OF XYLANASE PRODUCTION}

The effect of different variables like temperature, $\mathrm{pH}$, carbon source, nitrogen source, time of incubation on xylanase production by SSF using $P$. citrinum 9602 was optimized by OFAT.

Effect of temperature: Temperature effect on xylanase production was evaluated by incubation of the inoculated flask ( $1 \mathrm{~g}$ biomass substrate) at a range of $25^{\circ} \mathrm{C}-40^{\circ} \mathrm{C}$ for $6 \mathrm{~d}$. The enzyme was harvested using extraction buffer, centrifuged and the supernatant was analyzed for xylanase activity.

Effect of pH on enzyme production: To investigate the $\mathrm{pH}$ effect, the MMS media was adjusted to different $\mathrm{pH}$ of 3, 4, 5, 6 and 7 and sterilized and added to the flask containing the sterile biomass substrate. P. citrinum was inoculated I refers to flask and incubated for $6 \mathrm{~d}$ at $30^{\circ} \mathrm{C}$. Sampling was done after every $24 \mathrm{~h}$ and was assayed for enzyme activity.

Effect of carbon source: To assess the effect of carbon source $1 \%(\mathrm{w} / \mathrm{v})$ of glucose, xylose, maltose, sucrose, galactose and lactose, were added to the flask containing biomass moistened with MMS medium, inoculated and incubated at $30^{\circ} \mathrm{C}$ for $6 \mathrm{~d}$ and xylanase activity was determined.

Evaluation of effect of Nitrogen source: Effect of nitrogen source on xylanase production was evaluated by addition of $1 \%(\mathrm{w} / \mathrm{v})$ of yeast, peptone, urea, $\mathrm{NH}_{4} \mathrm{SO}_{4}$ and $\mathrm{NH}_{4} \mathrm{NO}_{3}$ to the media containing flask and incubated for $6 \mathrm{~d}$, sample was collected after every $24 \mathrm{~h}$, centrifuged and supernatant was quantified for xylanase.

Incubation period: Biomass containing MMS media is inoculated with $P$. citrinum and incubated at $30^{\circ} \mathrm{C}$. The enzyme was harvested on 2nd, 3rd, 4th, 5th, and 6th day and centrifuged at $7000 \mathrm{~g}$ for $20 \mathrm{~m}$ and the supernatant thus obtained was analyzed for maximum xylanase activity.

Moisture effect on xylanase production: To determine the percentage of moisture required for maximum xylanase production, substrate was moistened with MMS to $60 \%, 70 \%$, $80 \%$ and $90 \%$ and incubated for 6 days. Sampling was done after every $24 \mathrm{~h}$ and assayed for xylanase activity.

Statistical optimization using Response surface methodology: Response surface model using box Behnken matrix of 24 factorial design with 3 levels in 27 runs was designed to determine the influence of $\mathrm{pH}(\mathrm{A})$, incubation period (B), biomass (C) and moisture content (D) on xylanase production.

The xylanase activity represented in U/gds was measured as response and a second order polynomial model was designed as per equation 1, to evaluate the effect of variables on the response.

$\mathrm{Y}=\mathrm{b}_{0}+\sum \mathrm{biXi}+\mathrm{biiXi}_{2}+\sum \mathrm{bijXiXj} \mathrm{(1)}$

Where $\mathrm{Y}$ is the response (xylanase activity), b0 is the regression coefficient and bi, bii, bij coefficients estimated by the model for quadratic effect of coded variables (A,B,C,D) and $x i$ and $x j$ are process variables (Table-1).

The significance of a variable on xylanase production was analyzed using analysis of variance (Anova) from Minitab 17 statistical software. The second order polynomial relation between the variables and the response $\mathrm{Y}$ has been 
Table 1. Variables or factors optimized for xylanase production.

\begin{tabular}{|l|c|c|c|c|}
\hline \multicolumn{1}{|c|}{ Factors } & Symbol & $\mathbf{- 1}$ & $\mathbf{0}$ & $\mathbf{+ 1}$ \\
\hline pH & $\mathrm{A}$ & 4 & 5 & 6 \\
\hline Incubation period & $\mathrm{B}$ & 3 & 4 & 5 \\
\hline Biomass & $\mathrm{C}$ & 1 & 2 & 3 \\
\hline Moisture & $\mathrm{D}$ & $70 \%$ & $80 \%$ & $90 \%$ \\
\hline
\end{tabular}

represented by quadratic equation below

$$
\begin{array}{r}
Y=b_{o}+b_{1} A+b_{2} B+b_{3} C+b_{4} D+b_{11} A^{2}+b_{22} B^{2}+b_{33} C^{2}+b_{44} D^{2}+ \\
b_{12} A B+b_{13} A C+b_{14} A D+b_{23} B C+b_{24} B D+b_{34} C D--(2)
\end{array}
$$

$\mathrm{A}, \mathrm{B}, \mathrm{C}, \mathrm{D}$ are the coded variables, $\mathrm{pH}$, incubation, biomass, moisture where $a \mathrm{~b}_{0}, \mathrm{~b}_{1}, \mathrm{~b}_{2}, \mathrm{~b}_{3}, \mathrm{~b}_{4}, \mathrm{~b}_{11}, \mathrm{~b}_{22}, \mathrm{~b}_{33}, \mathrm{~b}_{44}, \mathrm{~b}_{12}, \mathrm{~b}_{13}, \mathrm{~b}_{14}, \mathrm{~b}_{23}$, $\mathrm{b}_{24}, \mathrm{~b}_{34}$ are co-efficient for various effects'.

\section{RESULTS AND DISCUSSION}

Initially a qualitative test was performed and the xylanolytic activity of the organism was confirmed by formation of clear zones on the agar plates containing MMS medium. Further various agro residues such as rice husk, corn fiber, wheat bran, cotton stalks and ground nut husk were screened for xylanase production by SSF. Maximum xylanase production of $275 \mathrm{U} / \mathrm{gds}$ was obtained using wheat bran as substrate, in comparison to oat spelt xylan. Hence in the current study wheat bran is selected as substrate in the place of oat spelt xylan for all further experiments. Wheat bran is generally used as a substrate for SSF due to its high nutritive value and good porosity. The results obtained in the current study are well in agreement with the reports of Saha and Gosh (2014) who observed maximum xylanase activity of $878 \mathrm{IU} / \mathrm{mL}$ from wheat bran using Penicillium citrinum xym2. Present studies are also in conformity with the earlier observations (Kavya and Padmavathi, 2009: Chandra et al., 2007; Nair et al., 2008) who reported wheat bran as potential substrate for high xylanase production. In line with the present observations, Pathak et al., (2014) also obtained higher amount of xylanase by SSF using wheat bran as substrate.

To obtain maximum xylanase production using wheat bran as a substrate, SSF fermentation was carried out by optimization of various parameters such as temperature, media $\mathrm{pH}$, nitrogen source, moisture content, co-substrate (additional carbon source) which induces xylanase production and incubation time by one factor at a time (OFAT). Among all the above parameters, temperature was found to be one of the regulatory factors affecting xylanase production. In the present work $30^{\circ} \mathrm{C}$ was found to be optimum temperature for maximum xylanase activity of $275 \mathrm{U} / \mathrm{gds}$. Variation in temperature range was found to affect the microbial development. Low temperature may cause decrease in the metabolism and consequently decreases enzyme production. However, extreme temperature may result in structural changes causing the enzyme denaturation (Pal and Khanum, 2010). Present investigations are in agreement with the earlier such findings of Amit Kumar et al., (2018) and Kumar et al., (2016), that SSF of wheat bran at $30^{\circ} \mathrm{C}$ results in maximum xylanase production of $786.53 \mathrm{IU} / \mathrm{gds}$ and 3592 IU/gds, respectively. However, Terrone et al., (2018) reported $20^{\circ} \mathrm{C}$ as an optimum temperature for highest xylanase production from sugarcane bagasse using Penicillium chrysogenum F-15, which is much on the lower side in comparison to the optimum temperature for maximum xylanase production evaluated during the present study. Temperature requirement seems to vary with the change in substrate.

When impact of co-substrate as an inducible carbon source on xylanase production was evaluated by supplementation of $1 \%$ of glucose, xylose, galactose, maltose, and lactose each to the wheat bran substrate, $1 \%$ maltose has shown maximum xylanase production of $285 \mathrm{U} / \mathrm{gds}$. Present results are consistent with the observation of Saha and Gosh (2014), who reported high xylanase activity of $1122 \mathrm{IU} / \mathrm{mL}$ by supplementation with $1 \%$ maltose.

When the effect of nitrogen source on xylanase production was investigated and maximum xylanase activity of $298 \mathrm{U} / \mathrm{gds}$ was obtained with the addition of $1 \%$ urea. Present studies are in conformity with the observations of Reis et al., (2015) that increased concentration of urea lead to increased xylanase production. However, our reports are in disagreement with the investigation of Javed et al., (2017) that organic nitrogen source like peptone is more effective for production of endo-1, 4- $\beta$ xylanase of $3069 \mathrm{U} \mathrm{mg-1}$ in comparison to inorganic nitrogen sources. The findings of the present study are also different with the observations of Saha and Gosh (2014) who reported xylanase activity of $1278 \mathrm{U} / \mathrm{ml}$ with di-ammonium hydrogen phosphate as nitrogen source.

The effect of incubation period on xylanase production was evaluated and, highest xylanase activity of $310 \mathrm{U} / \mathrm{gds}$ was observed after $96 \mathrm{~h}$ of incubation. As compared Saha and Gosh (2014) and Goshal et al., (2014) obtained highest xylanase activity of $1853 \mathrm{IU} / \mathrm{mL}$ after 72 hours of fermentation of wheat bran using $P$. citrinum xm2 and $156 \mathrm{IU} / \mathrm{mL}$ after $120 \mathrm{~h}$ of incubation using $P$. citrinum MTCC9620 of fermentation of sugarcane bagasse, respectively. Murthy and Naidu (2012) reported maximum enzymatic production at a fermentation period of $120 \mathrm{~h}$ by Pencillium sp. CFR 303 when coffee co products were used as substrates.

Moisture plays prominent role in xylanase production. Low moisture results in decrease in the nutrient solubility and cause high water stress which lead to less microbial growth and enzyme production hence optimum moisture content is necessary for maximum enzyme production. Presently highest xylanase production of $320 \mathrm{U} / \mathrm{gds}$ was acquired at $80 \%$ moisture level. These results are quite close to the results of Zhang and Sang (2015) who reported maximum xylanase production with $74 \%$ moisture level, by $P$. chrysogenum QML2 using wheat bran and corn powder mixture as substrate. However, in contrast to our report of $80 \%$ moisture for maximum xylanase activity, Amit Kumar et al., (2018) obtained maximum xylanase of $948.20 \mathrm{IU} / \mathrm{gds}$ at an initial moisture content of only $65 \%$ using wheat bran as substrate.

$\mathrm{pH}$ was found to show profound effect on xylanase production by fermentation of wheat bran by SSF. Evaluation of xylanase production at $\mathrm{pH}$ range of 4 to 7 showed a gradual increase in xylanase production with increase in $\mathrm{pH}$ and resulted in the highest xylanase activity of $345 \mathrm{U} / \mathrm{gds}$ at pH6. Our studies are comparable to the studies of Olanbiwoninu and Odunfa (2016) who documented maximum xylanase 
productions at pH 6.0 by Aspergillus terreus KJ829487 using cassava peels as the substrate and Goshal et al. (2014) who reported highest xylanase activity of $156 \mathrm{U} / \mathrm{mL}$ at an optimum $\mathrm{pH}$ of 6 , by shake flask fermentation of sugarcane bagasse using $P$. citrinum MTCC 9620. Contrary to the present observations, Saha and Gosh (2014) reported maximal xylanase activity of $1025 \mathrm{IU} / \mathrm{ml}$ at acidic $\mathrm{pH}$ of 4 . In comparison Ferraz et al., (2020) who obtained maximum xylanase activity by $P$. roqueforti at $\mathrm{pH} 3$.

SSF fermentation of wheat bran by using OFAT optimized parameters like $30^{\circ} \mathrm{C}$ temperature, media $\mathrm{pH}$ of 6 , maltose and urea with $80 \%$ moisture content and incubation time of 4 $\mathrm{d}$, maximum xylanase production of $405 \mathrm{U} / \mathrm{gds}$ was obtained. However, to further increase the xylanase production, Box Behnken statistical design was used for optimization of xylanase production parameters. Different combination of factors and their levels ( $\mathrm{pH} 4-6$, incubation period 3-5, biomass concentration 1-3 and moisture content 70-90) used in the experimental design to obtain maximum xylanase production is documented in table 2 . Final xylanase activity produced by collective effect of process variables is given in table 2. The coded variables are represented in the form of eq. 2. Results of statistical evaluation of the model using ANOVA are given in table 3. It is evident from the data presented in table 3 that the $p$ value of the model was less than 0.05 with respective $\mathrm{F}$ - value of 9.35 proving that the quadratic model is significant and can predict the data. However, other variables such as $\mathrm{pH}$, biomass, $\mathrm{pH}^{*} \mathrm{pH}$, incubation time * incubation time, moisture*moisture, appears to be highly significant with $p$ value $<0.05$. The second order polynomial regression equation below can be obtained using all the above results.

Xylanase $(\mathrm{U} / \mathrm{gds})=-13481+1047 \mathrm{~A}+696 \mathrm{~B}+815 \mathrm{C}+226.6$ $\mathrm{D}-101.2 \mathrm{~A} * \mathrm{~A}-120.6 \mathrm{~B} * \mathrm{~B}-31.3 \mathrm{C} * \mathrm{C}-1.580$ $\mathrm{D} * \mathrm{D}+43.7 \mathrm{~A} * \mathrm{~B}-139.3 \mathrm{~A} * \mathrm{C}+2.50 \mathrm{~A} * \mathrm{D}-$ $50.3 \mathrm{~B} * \mathrm{C}+2.02 \mathrm{~B} * \mathrm{D}+1.88 \mathrm{C} * \mathrm{D}$

In the current study coefficient of determination $\left(\mathrm{R}^{2}\right)$, adjusted $\mathrm{R}^{2}$, predicted $\mathrm{R}^{2}$ and 'Lack of Fit was used for consideration of

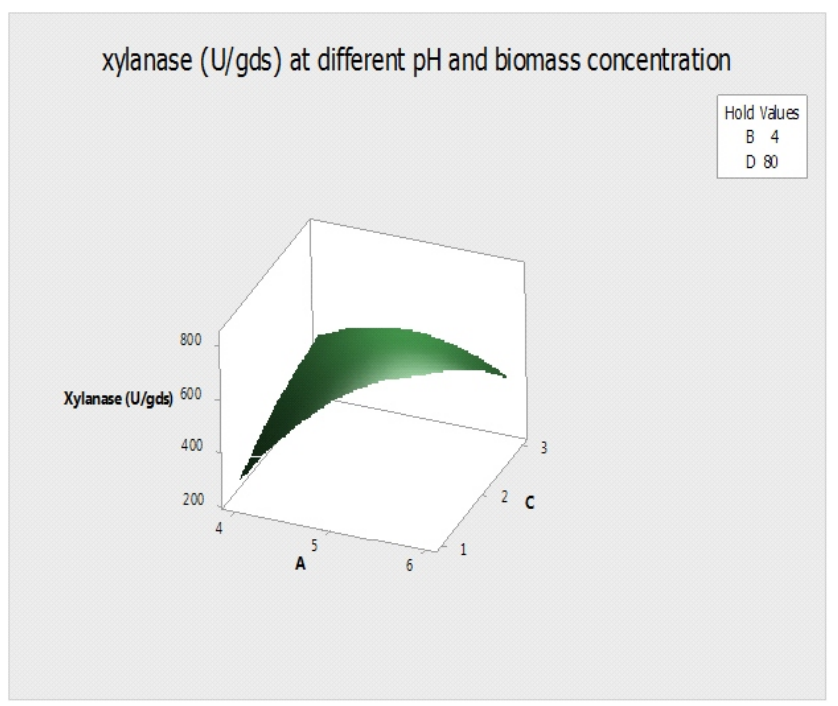

Fig.1a. Interaction of $\mathrm{pH}$ and biomass concentration on xylanase production
Table 2. Box Behnken design of process variables on xylanase production

\begin{tabular}{|c|c|c|c|c|}
\hline pH & $\begin{array}{c}\text { Incubation } \\
\text { time }\end{array}$ & Biomass & Moisture & $\begin{array}{c}\text { Xylanase } \\
\text { (U/gds) }\end{array}$ \\
\hline 4 & 3 & 2 & 80 & 300 \\
\hline 6 & 3 & 2 & 80 & 380 \\
\hline 4 & 5 & 2 & 80 & 295 \\
\hline 6 & 5 & 2 & 80 & 550 \\
\hline 5 & 4 & 1 & 70 & 475 \\
\hline 5 & 4 & 3 & 70 & 390 \\
\hline 5 & 4 & 1 & 90 & 400 \\
\hline 5 & 4 & 3 & 90 & 390 \\
\hline 4 & 4 & 2 & 70 & 277 \\
\hline 6 & 4 & 2 & 70 & 493 \\
\hline 4 & 4 & 2 & 90 & 222 \\
\hline 6 & 4 & 2 & 90 & 538 \\
\hline 5 & 3 & 1 & 80 & 490 \\
\hline 5 & 5 & 1 & 80 & 575 \\
\hline 5 & 3 & 3 & 80 & 505 \\
\hline 5 & 5 & 3 & 80 & 389 \\
\hline 4 & 4 & 1 & 80 & 289 \\
\hline 6 & 4 & 1 & 80 & 925 \\
\hline 4 & 4 & 3 & 80 & 356 \\
\hline 6 & 4 & 3 & 80 & 430 \\
\hline 5 & 3 & 2 & 70 & 406 \\
\hline 5 & 5 & 2 & 70 & 365 \\
\hline 5 & 3 & 2 & 90 & 300 \\
\hline 5 & 5 & 2 & 90 & 340 \\
\hline 5 & 4 & 2 & 80 & 667 \\
\hline 5 & 4 & 2 & 80 & 589 \\
\hline 5 & 4 & 2 & 80 & 620 \\
\hline \multicolumn{5}{|c|}{$\begin{array}{ll}\text { Box-Behnken Design } \\
\text { Factors: } 4 & \text { Replicates: } 1 \\
\text { Total runs: } 27 & \text { Base blocks: } 1 \\
\text { Center points: } 3 & \\
\end{array}$} \\
\hline
\end{tabular}

fit of model. $\mathrm{R}^{2}$ value of $91.6 \%$ in this study indicates variability of response and the better agreement of the data and the model. The predicted $\mathrm{R}^{2}$ of $53.5 \%$ and adjusted $\mathrm{R}^{2}$ $81.8 \%$ are well in harmony. F-value of 2.96 for lack of fit implies that it is insignificant, and the model is valid for the current study.

To recognize the most probable level of variables for highest xylanase activity and to find out the interaction between two variables by keeping the other variables constant the response surface plots are created Fig.1 (a, b).

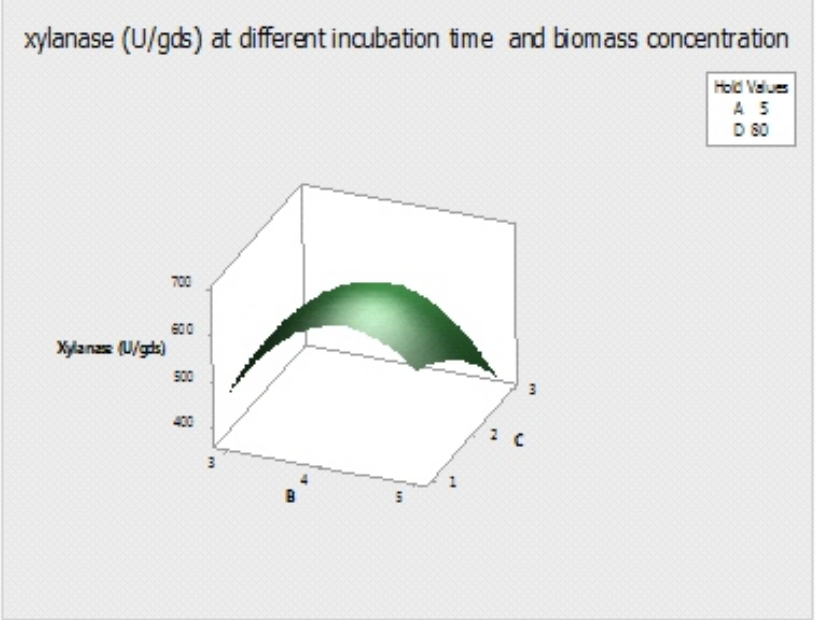

Fig.1b. Interaction of incubation time and biomass concentration on xylanase production 
Table 3. Response Surface Regression: Xylanase (U/gds) versus A, B, C, D

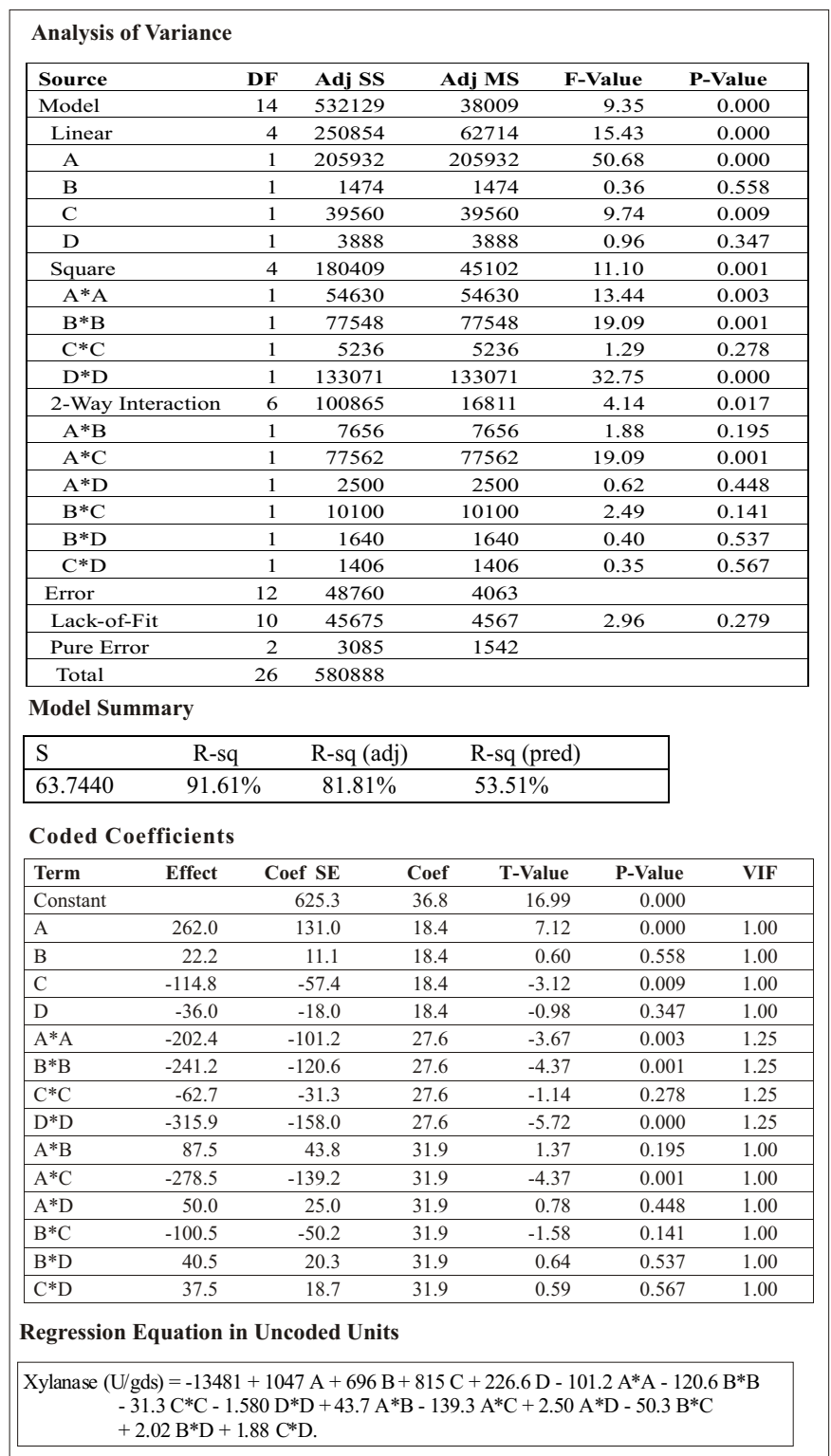

In the present study, the interaction between the variables $\mathrm{pH}$ and incubation period, $\mathrm{pH}$ and moisture, incubation period and biomass, incubation period and moisture, biomass and moisture do not have significant influence on the xylanase production represented by $\mathrm{P}>0.05$ (Table 3). However, $\mathrm{pH}$ and biomass have significant interaction and hence influence the xylanase production with $\mathrm{P}$-value $<0.05$ for AC (Table 3). Xylanase titer increased with increased $\mathrm{pH}$ and decreased biomass concentration.

In the present study statistical optimization using optimized factors, $\mathrm{pH} 6$, Incubation time 4d, biomass concentration $1 \mathrm{~g}$ and moisture content of $80 \%$ by Box Behnken design produced maximum Xylanase of $925 \mathrm{U} / \mathrm{gds}$.

Validation experiment designed using optimum levels of all the variables, $\mathrm{pH} 6$, incubation time of $4 \mathrm{~d}$, biomass content 1 g, $80 \%$ moisture level, respectively to attain maximum xylanase production resulted in the enhancement of the activity to $1225 \mathrm{U} / \mathrm{gds}$. Proving box behnken based RSM design to be accurate and reliable in enhancing xylanase production from wheat bran using $P$. citrinum by SSF. Bagewadi et al., (2016) obtained xylanase production of $30,144 \mathrm{U} / \mathrm{g}$ by RSM using variables like ammonium sulphate $0.36 \%$; yeast extract $0.6 \%$; $\mathrm{pH} 4$; temperature $40^{\circ} \mathrm{C}$ yielding from sweet sorghum bagasse. The results of this study by Bagewadi et al., (2016) documented higher yield of xylanase in comparison to the results of our study. However, in comparison to the study of $\mathrm{Xu}$ et al., (2008), who reported xylanase production of $46.5 \mathrm{U} / \mathrm{mL}$, by fermentation of wheat bran with Penicillium sp. WX-Z1 using Box Behnken design, the presently evaluated amount of xylanase was on the higher side.

\section{CONCLUSION}

Utilization of wheat bran as a lignocellulosic substrate proved to be efficient and on par with any other lignocellulosic biomass used for xylanase production. Use of agro residues will contribute to reduce the production cost making the entire process economical.

\section{ACKNOWLEDGEMENTS}

We are thankful to UGC-DRS-I (SAP-II) for providing the financial support.

\section{REFERENCES}

Amit Kumar, B., Kumar, A., Kumar, A. and Dutt, D. 2018. Wheat bran fermentation for the production of cellulase and xylanase by Aspergillus niger NFCCI 4113. Res. J. Biotech. 13(5): 10-18.

Bailey, M. J., Biely, P. and Poutanen, K. 1992. "Inter laboratory testing of methods for assay of xylanase activity". Journal of Biotechnology 23(3): 257-270.

Chadha, B. S., Kaur, B., Basotra, N., Tsang, A. and Pandey, A. 2019. Thermostable xylanases from thermophilic fungi and bacteria: current perspective. Bioresour. Technol. 277:195-203.

Chandra, M.S., Viswanath, B. and Reddy, B.R. 2007. Cellulolytic enzymes on lignocellulosic substrates in solid state fermentation by Aspergillus niger. Indian Journal of Microbiology 47: 323-328.

Dos Reis, L., Ritter, C. E. T., Fontana, R. C., Camassola, M. and Dillon, A. J. P. 2015. Statistical optimization of mineral Salt and urea concentration for cellulase and xylanase production by penicillium echinulatum in submerged Fermentation. Brazilian Journal of Chemical Engineering 32(1): 13 - 22.

dos Santos, T. C., Filho, G. A., de Brito, A. R., Pires, A. J. V., Bonomo, R. C. F., and Franco, M. 2016. Production and characterization of cellulolytic enzymes by Aspergillus niger and Rhizopus sp. by solid state fermentation of prickly pear. Rev. Caatinga 29: 222233.

Ghoshal, G., Banerjee, U. C and Shivhare, U. S. 2014. Xylanase Production by Penicillium citrinum in Laboratory-scale Stirred Tank Reactor. Chem. 
Biochem. Eng. Q28(3): 399-408.

Govarthanan, M., Selvankumar, T., Selvam, K., Sudhakar, C., Aroulmoji, V. and Kamala-Kannan, S. 2015. Response surface methodology-based optimization of keratinase production from alkali-treated feather waste and horn waste using Bacillus sp. MGMASC-BT. J. Ind. Eng. Chem. 27: 25-30.

Gupta, R., Khasa, Y.P, Kumar, A. Shrivastava and B., Kuhad, R.C. 2012. Xylanase production from an alkalophilic actinomycete isolate Streptomyces sp.RCK-2010, its characterization and application in saccharification of second-generation biomass. $J$. Mol. Cata.. B: Enzym. 74: 170-177.

Javed, U., Aman, A. and Qader, S.A.U. 2017. Utilization of corncob xylan as a sole carbon source for the biosynthesis of endo-1,4- $\beta$ xylanase from Aspergillus niger KIBGE-IB36, Bioresources and Bioprocessing 4: 1-7.

José Lucas de Almeida Antunes Ferraz, Lucas Oliveira Souza, André Gustavo de Araújo Fernandes, Marcio Luiz Ferreira Oliveira, Julieta Rangel de Oliveira and Marcelo Franco 2020. Optimization of the solidstate fermentation conditions and characterization of xylanase produced by Penicillium roqueforti ATCC 10110 using yellow mombin residue (Spondias mombin L.). Chemical Engineering Communications 207(1): 31-42. DOI: 10.1080/ 00986445.2019.1572000

Kandasamy, S., Muthusamy, G., Balakrishna, S., Duraisamy, S., Seralathan, K. K., and Sudhakar, C. 2016. Optimization of protease production from surfacemodified coffee pulp waste and corncobs using Bacillus sp. By SSF. 3 Biotech. 6:16.

Kavya, V. and Padmavathi, T. 2009. Optimization of growth conditions for xylanase production by Aspergillus niger in solid state fermentation. Polish Journal of Microbiology 58: 125-130.

Knob, A., Fortkamp, D., Prolo, T., Izidoro, S. C. and Almeida, J. M. 2014. Agro-residues as alternative for xylanase production by filamentous fungi. Bio. Resources 9: 5738-5773.

Kumar, A., Gautam, A. and Dutt, D. 2016. Co-cultivation of Penicillium sp. AKB-24 and Aspergillus nidulans AKB-25 as a cost-effective method to produce cellulases for the hydrolysis of pearl millet stover. Fermentation 2: 1-22.

Lowry, O.H., Rosebrough, NJ., Farr, A.L., et al., 1951. Protein measurement with the Folin phenol reagent. J. Biol. Chem. 193:265-275.

Maheshwari, R., Bharadwaj, G. and Bhat, M.K. 2000. Thermophilic fungi: their physiology and enzymes. Microbiol. Mol. Rev. 64: 461-488

Mandels, M. and Reese, E. T. 1957. Induction of cellulase in Trichoderma viride as influenced by carbon source and metals. Journal of Bacteriology 73: 269-278.

Miller, G.L. 1959. Use of dinitrosalicylic acid reagent for determination of reducing sugar. Anal. Chem. 31(3): 426-429. https://doi.org/10.1021/ac60147a030.

Murthy, P. S., and Naidu, M. M. 2012. "Production and application of xylanase from Penicillium sp. utilizing coffee by-products". Food Bioprocess Technol.5(2): 657-664.

Olanbiwoninu, A.A., and Odunfa, S.A. 2016. Production of cellulase and xylanase by Aspergillus terreus KJ829487 using Cassava peels as subtrates. Advances in Microbiology 6: 502-511.

Pal, A. and Khanum, F. 2011. Covalent immobilization of xylanase on glutaraldehyde activated alginate beads using response surface methodology: characterization of immobilized enzyme. Process Biochem. 46:1315-1322.

Pandiyan, K., Singh, A., Singh, S., Saxena, A. K. and Nain, L. 2019. Technological interventions for utilization of crop residues and weedy biomass for second generation bio-ethanol production. Renew. Energy 132: 723-741.

Pathak, P., Bhardwaj, N.K. and Singh, A.K. 2014. Production of crude cellulase and xylanase from Trichoderma harzianum PPDDN10 NFCCI-2925 and its application in photocopier wastepaper recycling. Appl. Biochem. Biotech. 172(8): 3776-3797. doi:10. 1007/s12010-014-0758-9.

Pruckler, M., Siebenhandl-Ehn, S., Apprich, S., Höltinger, S., Hass, C., Schmid, E., and Kneifel, W. 2014. "Wheat bran-based biorefinery 1: Composition of wheat bran and strategies of functionalization". LWT-Food Sci. Technol.56(2): 211-221.

Saha, S.P. and Ghosh, S. 2014. Optimization of xylanase production by Penicillium citrinum xym2 and application in saccharification of agro-residues. Biocatal. Agric. Biotechnol. 3:188-196.

Santala, O., Lehtinen, P., Nordlund, E., Suortti, T., and Poutanen, K. 2011. "Impact of water content on the solubilization of arabinoxylan during treatment of wheat bran". J. Cer. Sci. 54 (2): 187-194.

Sharma, M. and Kumar, A. 2013. "Xylanases: An overview". British Biotechnol. J. 3 (1): 1-28.

Suprabha, G., Nair., Sindhu, R. and Shankar Shashidhar. 2008. Fungal xylanase production under solid state and submerged fermentation conditions. African Journal of Microbiology 2: 082-086.

Terrone, C. C., de Freitas, C., Terrasan, C. R. F., de Almeida, A. F. and Carmona, E. C. 2018. Agro industrial biomass for xylanase production by Penicillium chrysogenum: purification, biochemical properties and hydrolysis of hemicelluloses. Electron. J. Biotechnol. 33: 39-45. 
Xu, Y.X., Li, Y.L., and Tang, J.W. 2008. "Improvement of xylanase production by Aspergillus niger XY-1 using response surface methodology for optimizing the medium composition". J. Zhejiang Univ. Sci. B. 9(7): 558-566.

Zabin, K., Bagewadi, Sikandar, I. M., Yogesh, S. and Harichandra, Z. N. 2016. Xylanase production from Penicillium citrinum isolate HZN13 using response surface methodology and characterization of immobilized xylanase on glutaraldehyde-activated calcium-alginate beads. 3 Biotech. 6:164. DOI 10. 1007/s13205-016-0484-9.

Zhang, H. and Sang, Q. 2015. Production and extraction optimization of xylanase and b-mannanase by Penicillium chrysogenum QML-2 and primary application in saccharification of corn cob. Biochem. Eng. J. 97: 101-110. 